\title{
Ensino de Ciências e CTS: Contribuições ao Aperfeiçoamento de Situações de Aprendizagem sobre Entropia e Degradação de Energia
}

(Science Education and STS: Contributions to the Improvement of Learning Situations of Entropy and Degradation of Energy)

\section{DANILO ROTHBERG ${ }^{1}$ e GABRIEL AUGUSTO CAÇÃO QUINATO ${ }^{2}$}

\author{
${ }^{1}$ Universidade Estadual Paulista (danilo@faac.unesp.br) \\ ${ }^{2}$ Instituto Federal do Paraná (gabriel_quinato@yahoo.com.br)
}

\begin{abstract}
Resumo. Nas práticas de Ensino de Ciências situadas sob a influência da convergência interdisciplinar de CTS, deve ser contemplada a formação para cidadania, pensada nos termos da participação democrática na formulação e avaliação de políticas de ciência e tecnologia. Este artigo apresenta os resultados de estudo empírico acerca da viabilidade de aperfeiçoamentos das Situações de Aprendizagem referentes ao Tema 'Entropia e Degradação da Energia' dos Cadernos do Professor e do Aluno para o Ensino de Física, material didático do Ensino Médio do Estado de São Paulo, $2^{\mathrm{a}}$ série, volume 2, 2009. As propostas de reformulação experimental do material foram avaliadas através da realização de grupos focais compostos por professores de Ciências. Os resultados indicam que as mudanças sugeridas no material foram, em geral, bem aceitas pelos professores participantes dos grupos focais, com ressalvas, no entanto, à viabilidade de sua aplicação no quadro das atuais limitações da escola e da formação docente.
\end{abstract}

Abstract. In Science Teaching practices situated under the influence of the interdisciplinary convergence of STS, citizenship education should be included, in terms of the democratic participation in the formulation and assessment of science and technology policies. This article presents the results of an empirical study about the feasibility of improvements to the learning situations on the theme 'Entropy and Degradation of Energy' of Physics teaching materials and course book made as part of the Programmatic Content of Curriculum of the São Paulo State, 2nd series, volume 2, 2009. The proposed experimental changes in the material were evaluated by focus groups composed of science teachers. The results indicate that the changes were generally well accepted by teachers participating in the focus groups, although with reservations about the feasibility of its deployment in the context of the current limitations of schools and teacher training.

Palavras-chave: ensino de ciências, CTS, material didático, formação para cidadania

Keyword: science education, STSE, teaching materials, citizenship

\section{Introdução}

Afirma-se no cenário contemporâneo dos estudos situados na convergência interdisciplinar entre Ciência, Tecnologia e Sociedade a perspectiva de que a dinâmica das interações entre os processos de avanço do conhecimento e as esferas decisórias das sociedades democráticas deve ser considerada na dimensão escolar da formação para a cidadania. Dar condições para que o cidadão possa interagir ativamente com a sociedade nas esferas da formulação de políticas públicas e das decisões sobre o desenvolvimento e as aplicações de ciência e tecnologia tem se mostrado um objetivo importante a ser alcançado no mundo contemporâneo, destacando-se inclusive a responsabilidade da Educação para a Ciência nesse cenário.

Ao passo que as democracias contemporâneas passaram a criar, gradativamente, espaços, oportunidades e procedimentos para que o público em geral possa compreender 
e expressar suas opiniões sobre as decisões de gestão pública que geram impacto sobre o uso cotidiano de ciência e tecnologia, no caso brasileiro a participação democrática na formulação de políticas da área tem sido concretizada, com frequência, através de consultas públicas realizadas pela internet. As consultas se apresentam como oportunidades de participação pública na formulação de políticas. Um setor governamental submete uma versão preliminar de um conjunto de princípios ou plano de ação para consulta online, possibilitando que indivíduos e atores sociais contribuam com críticas e sugestões, de modo a gerar subsídios para a formulação compartilhada de políticas públicas.

Embora as consultas públicas sejam realizadas com frequência crescente pelo governo brasileiro e envolvam diversos temas de ciência e tecnologia, constituindo um importante meio de ampliação da cidadania, permanece em aberto a caracterização da formação e da informação necessárias à participação política através desses instrumentos de democratização da gestão pública. De que maneira o ensino formal poderia contribuir para a preparação de indivíduos aptos a compreender as questões em jogo e expressar suas perspectivas em consultas públicas? Como o Ensino de Ciências Naturais poderia comportar o desenvolvimento de situações de aprendizagem que envolvam o tratamento de questões relativas à compreensão das escolhas subjacentes às políticas nacionais de ciência e tecnologia? De que maneira aspectos da formação para a cidadania, considerada como exercício de direitos civis, políticos e sociais nas sociedades democráticas contemporâneas, poderiam ser contemplados pelo Ensino de Ciências Naturais, de modo a oferecer uma contribuição ao desenvolvimento do cidadão nos demais espaços da vivência cotidiana?

Para buscar respostas a estas questões de pesquisa, reunimos conhecimentos relevantes ao tema e sugerimos aperfeiçoamentos do material didático produzido pela Secretaria de Educação do Estado de São Paulo para a rede pública do Ensino Médio, especificamente para o Tema 3, "Entropia e Degradação de Energia", presente nos Cadernos do Professor e do Aluno para o Ensino de Física, parte integrante da Proposta Curricular do Ensino Médio do Estado de São Paulo, $2^{a}$ série, volume 2, 2009. As reformulações experimentais propostas fazem referência ao PDE - Plano Decenal de Expansão de Energia 2020, posto em consulta pública pelo Ministério de Minas e Energia em junho de 2011 e aprovado pela Portaria n. 689, de 28 de dezembro de 2011. O documento, que aborda questões de demanda e produção de energia para o Brasil no período de 2011 a 2020, foi parte de um processo de formulação compartilhada de 
políticas de ciência e tecnologia ligadas ao tema em questão e ofereceu uma oportunidade para pensar a contribuição do material didático à formação cidadã e à preparação para participar na produção de políticas públicas.

Posteriormente, apresentamos a proposta do material experimental a professores de Física que poderiam utilizá-lo em sua prática docente na rede pública de educação do Estado de São Paulo, em perspectiva comparativa com o material original. Coletamos, através da metodologia de grupo focal, opiniões, sugestões e críticas sobre as mudanças propostas e sua aplicabilidade.

Este artigo apresenta os resultados desta pesquisa, dividindo-se em quatro partes. Em primeiro lugar, aspectos teóricos fundamentais são revisados. Em segundo lugar, as metodologias de pesquisa empregadas são caracterizadas. Em terceiro lugar, apresentamos uma síntese dos resultados dos grupos focais, com as opiniões e perspectivas dos professores sobre as propostas de intervenção no material didático. Por fim, considerações finais sintetizam as contribuições do artigo. Notamos que as mudanças experimentais propostas aos Cadernos do Aluno e do Professor foram, em geral, bem aceitas pelos professores participantes dos grupos focais, com ressalvas, no entanto, à viabilidade de sua aplicação no quadro das atuais limitações da escola e da formação docente.

\section{Aspectos teóricos fundamentais}

O Ensino de Ciências pensado à luz dos saberes reunidos na intersecção conhecida como CTS (Ciência, Tecnologia, Sociedade) se articula em torno de considerações sobre a produção e a gestão de ciência e tecnologia (C\&T) como "um processo não neutro, impossível de ser separado de sua interação social, onde os elementos não técnicos envolvidos possuem papel fundamental na sua gênese e consolidação" (LÓPEZ CEREZO, 2004, p. 15).

No contexto, a ciência é considerada uma atividade humana altamente complexa, sofrendo influência de seus elementos não técnicos, e não como um processo autônomo e isolado da sociedade (SOUZA et al., 2008; SANTOS; ICHIKAWA, 2004; SANTOS; MORTIMER, 2002; GONZÁLEZ GARCÍA et al., 1996; HAYASHI et al., 2008). A educação deve contribuir através da formação de indivíduos aptos à tomada de decisões de maneira informada e responsável, possibilitando a ação sobre essas decisões (PEDRETTI, 2003; CHASSOT, 2003; BERNARDO et al., 2011). 
A educação assume como objetivos desmistificar a visão clássica de C\&T como um saber superior, inquestionável e portador de verdades absolutas, e incorporar aspectos do desenvolvimento sustentável que devem ser submetidos à tomada de decisões nos sistemas democráticos de forma crítica e informada. Torna-se relevante pavimentar o desenvolvimento de uma atitude de vigilância crítica diante de fatos sociais que envolvam gestão de C\&T, necessária para a participação nos processos de produção de políticas públicas (PEDRETTI, 2003; AULER, 2003). Espera-se que os alunos "possuam um mínimo de conhecimentos científicos específicos sobre a problemática estudada, sem os quais é impossível compreender as opções em jogo e participar na tomada de decisões fundamentadas" (PRAIA et al., 2007, p. 143).

No âmbito das práticas docentes, torna-se necessário encorajar o trabalho com questões abertas ao debate, de caráter interdisciplinar, controversas, que envolvam questões éticas e de valores (PEDRETTI et al., 2008). A preparação didática deve incluir planejamento de atividades como debates, estudos de caso e simulações.

Mas os obstáculos não são poucos. Segundo Hodson (2003, p. 664), o Ensino de Ciências tem incluído somente "conhecimentos seguros e bem estabelecidos, enquanto que conhecimento contestável, múltiplas respostas e questões controversas e éticas têm sido excluídas". Para Pedretti et al. (2008), os professores resistem a abandonar sua posição de controle e conceder autonomia aos alunos. A própria possibilidade de o professor não saber a resposta para uma questão aberta, ou ainda a responsabilidade de se trabalhar com questões nas quais não existam certo e errado, mas sim apenas posicionamentos divergentes, assusta muitos professores.

Auler e Delizoicov (2001) apontam a existência de três mitos relacionados às interações entre CTS e educação científica, visíveis na aceitação de ideias que nem sempre condizem com a atividade científico-tecnológica. Como primeiro mito, está a crença na superioridade do modelo de decisões tecnocráticas, que tende a considerar a ciência e tecnologia como superiores e neutras, que teriam como único objetivo o desenvolvimento pleno e a busca pelo progresso, incapazes de serem corrompidas e independentes de decisões democráticas. São desconsiderados fatores importantes, tais como o cenário sociopolítico em que as decisões são tomadas. $\mathrm{O}$ cientista e o especialista são os mais indicados para tomar decisões, uma vez que possuem o conhecimento técnico necessário e estão livres de qualquer influência social, buscando simplesmente a melhor saída possível para qualquer problema (AULER; DELIZOICOV, 2001). 
A tecnocracia reforça uma visão de mundo na qual se reduz o espaço para a democracia nas decisões que afetam a produção e a aplicação de tecnologia. A participação pública é vista como um elemento que causa incertezas e abre espaço para questionamentos, que alegadamente não poderiam existir com relação à C\&T.

$\mathrm{O}$ segundo mito subjaz à perspectiva salvacionista atribuída à ciência e tecnologia, segundo a qual os problemas sociais seriam resolvidos meramente pelo avanço da C\&T. Se em dado momento não existirem C\&T capazes de resolvê-los, em outro momento elas serão desenvolvidas para tal, ignorando-se a não neutralidade das políticas e a necessária participação social na busca de soluções (AULER; DELIZOICOV, 2001).

O terceiro mito reside no determinismo tecnológico que prega a tecnologia como causa das mudanças na sociedade, alheia ao cenário sócio-econômico-político. Acredita-se que o homem e a sociedade são produtos e consequências do desenvolvimento tecnológico; a inovação tecnológica é boa por si própria e levará necessariamente a um maior desenvolvimento socioeconômico. A ciência e tecnologia são vistas como entidades acima do bem e do mal, de forma a ocorrer uma diminuição da responsabilidade humana sobre seus efeitos. Estes mitos, que compartilham uma visão de ciência neutra, livre de pressões e influências sociais, trariam para o Ensino de Ciências a valorização da tecnocracia, em prejuízo da democracia. Reduz-se o espaço para discussão de problemas e projeta-se a busca por uma resposta ótima e eficiente a ser aplicada (AULER; DELIZOICOV, 2001; WERTHEIN; CUNHA, 2009).

Pedretti (2003), em pesquisa realizada no Canadá com professores recémformados ou em processo de formação, realizou uma série de entrevistas no intuito de elucidar suas concepções sobre CTS e a possibilidade de sua utilização como fonte de saberes para a prática docente. Os entrevistados relataram dificuldades quando buscam relacionar o conhecimento científico à tomada de decisões na esfera da política democrática relativas às prioridades de produção e aplicação de C\&T. Os professores, com frequência, não são preparados para trabalhar com questões políticas, sociais e culturais subjacentes aos conceitos científicos que abordam. Mesmo que eles se interessem por CTS, tendem a renunciar à possibilidade de aprofundar-se no campo e desenvolver didáticas compatíveis. Apesar de focar professores canadenses, a pesquisa revela uma realidade que pode ser comum em outras partes do globo.

No Brasil, há indicações similares. Pierson et al. (2007) apresentaram três possíveis dinâmicas de aula para alunos do quarto ano de Licenciatura em Química de 
uma universidade pública do Estado de São Paulo, uma delas com enfoque sobre as relações entre Ciência, Tecnologia e Sociedade, e avaliaram as perspectivas dos estudantes sobre elas. Dez entre quinze licenciandos avaliaram positivamente a aula CTS. As ressalvas mencionaram o risco de tal abordagem prejudicar a transmissão de todo o conteúdo previsto para determinado tema, levando os autores à reflexão de que "os futuros professores e professoras ainda não conseguiram desvincular-se da concepção de que o que forma é a quantidade de informação transmitida aos estudantes" (PIERSON et al., 2007, p. 9).

Diante de tais insuficiências, a prática do Ensino de Ciências sustentada por perspectivas CTS viria, por exemplo, por meio da criação de estratégias pedagógicas que associem conteúdos curriculares atualmente existentes às dinâmicas dos processos sociais de formulação de políticas de ciência e tecnologia. Daí advém a relevância de enfocar, em sala de aula, temas que, por sua própria novidade e subordinação a processos políticos de regulação em curso, requerem um tratamento adequado na esfera escolar, como descarte de materiais radioativos, formas mais limpas de obtenção de energia, nanotecnologia, biotecnologia e células-tronco.

No estudo de exploração do que ainda não é definitivo, pode-se buscar a formação para a democracia; se, na escola, o aluno adquirir o hábito de investigar implicações e controvérsias científicas, posicionando-se criticamente frente a elas, pode-se esperar que, nas interações sociais extraescolares, terá mais possibilidades de exercer seus direitos de cidadania enquanto cidadão participativo (ACEVEDO, 2004; ACEVEDO et al, 2005; AIKENHEAD, 2003; LEVINSON, 2008; LEITE; FERRAZ, 2011).

Entre as diversas temáticas de ciência e tecnologia presentes nos processos sociais de formulação de políticas públicas na atualidade, consideramos uma em particular como oportuna para o desenvolvimento de abordagens pedagógicas apropriadas ao enfoque CTS, relacionada a um conteúdo contemplado pelo currículo escolar das escolas paulistas de nível médio. Trata-se do tópico de produção e consumo de energia elétrica, incluído nos Cadernos do Aluno (SÃO PAULO, 2009a) e do Professor (SÃO PAULO, 2009b), que pode ser examinado à luz de uma dinâmica bastante atual dos processos de produção de políticas de ciência e tecnologia, consubstanciada no Plano Decenal de Expansão de Energia 2020 (BRASIL, 2011c), posto em consulta pública através da internet pelo Ministério de Minas e Energia em junho de 2011 e aprovado pela Portaria n. 689, de 28 de dezembro de 2011. 
As consultas públicas online são meios de construção compartilhada de diretrizes de políticas públicas e legislações. Um setor governamental submete uma versão inicial do texto sob consulta pela internet, e indivíduos e setores podem "se manifestar sobre cada aspecto proposto, indicar a necessidade de mudanças, justificar o porquê das sugestões, conhecer as contribuições de outros participantes, rever seus conceitos após descobrir as posições alheias, combinar-se com outros para conjuntamente propor alterações" (ROTHBERG, 2010, p. 70).

As consultas públicas são uma inovação recente do processo político brasileiro, e nem sempre estão claros seus objetivos, públicos-alvo e resultados esperados (ROTHBERG, 2008). No entanto, elas indicam que o país, a exemplo da Europa e dos Estados Unidos, começa a reconhecer que as políticas públicas de diversas áreas, entre elas a ciência e a tecnologia, não podem prescindir da participação pública em sua formulação, se pretendem ser eficientes e eficazes. Se em muitos países a transparência e a participação na produção de políticas de ciência e tecnologia obedecem a um requisito legal (IRWIN, 2008), no Brasil já se identifica uma tendência recente de realização de consultas públicas de políticas da área.

A educação científica pode se beneficiar desse quadro. Os processos formais de Ensino de Ciências podem ser enriquecidos através de práticas pedagógicas que, em busca de meios para tornar mais atraentes as situações de aprendizagem, façam correlações com os mecanismos democráticos disponíveis atualmente para socializar a decisão em torno de políticas públicas de ciência e tecnologia, em particular aquelas de grande impacto econômico e social, como as relativas à produção de energia.

O Plano Decenal de Expansão de Energia 2020 (PDE 2020), elaborado pelo Ministério de Minas e Energia (MME) em conjunto com a Empresa de Pesquisa Energética (EPE), delineia uma previsão de como se comportará a expansão da demanda e da oferta de energia no Brasil no período compreendido entre 2011 e 2020 (BRASIL, 2011b; 2011c).

O documento apresenta projeções de demanda em relação a aspectos como os dividendos do desenvolvimento industrial e socioeconômico do país, com maior número de domicílios, produção e mercado de bens de consumo. O plano propõe formas de atendimento ao aumento esperado de demanda, considerando fatores como a inclusão de novas geradoras (Belo Monte), o potencial de exploração da camada do pré-sal, a melhoria da eficiência de linhas de transmissão; inclusão de fontes renováveis e troca de equipamentos antigos por outros mais eficientes. Referências ao PDE 2020 em sala de 
aula seriam férteis, de modo a possibilitar uma abordagem interdisciplinar sobre aspectos como as resistências à construção de Belo Monte, a compra de energia elétrica excedente de outros países e as relações sociopolíticas envolvidas, a eficiência do gás natural e de combustíveis renováveis etc.

Ao contrário de muitos casos de formulação de políticas públicas de ciência e tecnologia cruciais nos Estados Unidos e países da Europa Ocidental, nos quais consultar os setores sociais envolvidos foi uma obrigação fixada por lei (FELT; WYNNE, 2007), no Brasil se admite a construção de políticas em círculos fechados e não transparentes. Mas a escassez de informações sobre como elas são decididas começa a ser transformada pela circulação de documentos como o PDE $2020 \mathrm{em}$ consultas públicas pela internet, que abre inclusive oportunidade para dinamizar o Ensino de Ciências.

De acordo com o currículo do Estado de São Paulo, no que diz respeito às ciências da natureza e suas tecnologias, os temas relacionados à energia e seus possíveis usos devem ser trabalhos na segunda série do ensino médio, no primeiro e segundo bimestres, sendo que o tema "Entropia e Degradação de Energia" é classificado como específico do segundo bimestre como conteúdo curricular da grade de Física (SÃO PAULO, 2010). Esse material didático, que possui elevado grau de detalhamento e especificação e busca direcionar a prática docente, com frequência tende a buscar a aproximação entre o que é tratado na escola e o cotidiano dos alunos, com uma abordagem diferenciada, baseada em atividades a serem executadas dentro ou fora da sala de aula, que não se esgota na mera transmissão de conceitos (SOUZA, 2006). Durante as atividades previstas, os alunos devem ter contato com conceitos básicos relacionados ao princípio de conservação da energia, fontes de energia tradicionais e alternativas, transformações energéticas e noções básicas de termodinâmica, de forma a compreender como esses conteúdos estão presentes no cotidiano e afetam a sociedade.

Estes aspectos compõem um contexto adequado ao aprofundamento sob o enfoque CTS, que avance no sentido de incluir temas atuais a fim de contribuir para o desenvolvimento de competências de leitura crítica da realidade contemporânea. Conteúdos relacionados ao funcionamento de uma usina hidrelétrica, por exemplo, podem ser complementados com análises da eficiência de produção de energia por essa via e de sua distribuição, dos custos envolvidos na sua instalação e sua comparação com investimentos necessários às reformas das usinas já existentes para se chegar a um aumento na produção de energia equivalente ao que será produzido por Belo Monte. As 
abordagens em sala de aula em sintonia com as demandas por conhecimento trazidas pela consulta pública do PDE 2020 envolveriam também análises da possibilidade de que fontes mais limpas e menos impactantes possam ser desenvolvidas no país, como solar, eólica, de biomassa, de marés etc., e comparações entre a matriz energética nacional e a de países como EUA, Inglaterra, Alemanha, França e Japão, nos aspectos de eficiência, grau de periculosidade, custo de produção e tecnologias envolvidas.

A referência em sala de aula aos processos de formulação de políticas públicas de ciência e tecnologia, dos quais o PDE 2020 é um importante exemplo na atualidade, também possibilitaria a aproximação do ensino ao que é preconizado pela Lei de Diretrizes e Bases da Educação Nacional em seu artigo 36 , segundo o qual “o currículo do ensino médio [...] destacará a educação tecnológica básica, a compreensão do significado da ciência (e) o processo histórico de transformação da sociedade" (BRASIL, 1996), e pelas orientações curriculares para o Ensino Médio (BRASIL, 2006), segundo as quais o enfoque CTS “possibilita a discussão da relação entre os polos que a sigla designa e a relevância de aspectos tecnocientíficos em acontecimentos sociais significativos" e "envolve ainda reflexões no campo econômico e sua articulação com o desenvolvimento tecnológico e científico".

\section{Aperfeiçoamento das Situações de Aprendizagem}

Elaboramos indicações ao aperfeiçoamento das Situações de Aprendizagem sobre o Tema "Entropia e Degradação da Energia", presente nos Cadernos do Professor e do Aluno para o Ensino de Física, parte integrante da Proposta Curricular do Ensino Médio do Estado de São Paulo, 2a série, volume 2, 2009, buscando sua adequação à educação científica com enfoque CTS e empregando como referência o Plano Decenal de Expansão de Energia 2020, documento submetido à consulta pública, considerado uma oportunidade de formulação compartilhada de políticas de ciência e tecnologia ligadas ao tema em questão.

Em busca de oportunidades de aperfeiçoamento do material didático em questão, o estudo descrito neste artigo identificou, no total, 24 inserções ou substituições possíveis de questões e conteúdos capazes de fundamentar a formação para a cidadania, pensada nos termos de qualificação para participação política em uma consulta pública que abranja temas ligados a C\&T. Esse total de intervenções foi efetivamente realizado nas Situações de Aprendizagem 7 e 8, em ambos os Cadernos (Aluno e Professor), de forma a gerar uma versão diferenciada do material didático, posteriormente distribuída 
para apreciação, com as alterações devidamente sinalizadas, dos professores participantes dos grupos focais que conduzimos. As mudanças propostas se dividiram em cinco dimensões, a saber:

1) Formulação de novas questões para conteúdos já disponíveis (3 inserções): identificamos a possibilidade de as Situações de Aprendizagem comportarem, da forma como se apresentam, novas questões, a fim de estimular os alunos à reflexão, em especial, sobre como a irreversibilidade dos processos de produção de energia - tópico já presente no material didático - é um fenômeno natural que, no Ensino de Ciências, não deveria ser dissociado de suas profundas implicações para a gestão pública. $\mathrm{Na}$ elaboração das questões, buscamos maximizar as relações conceituais com os conteúdos apresentados.

Uma questão presente no Caderno do Aluno (2009a) exemplifica esta frente de mudanças propostas. A questão instava de forma genérica o aluno a dar "um exemplo diferente dos que foram tratados em aula entre energia organizada e energia desorganizada". No material reformulado experimentalmente, esta questão foi substituída por esta versão:

Com relação aos processos de transformação de energia que são considerados irreversíveis, como por exemplo, o aquecimento presente no processo de funcionamento de motores à combustão, como essa impossibilidade de reversão afeta os processos humanos de produção e transformação de energia? Em sua opinião, as discussões acerca dessa irreversibilidade são questões puramente científicas ou também afetam setores econômicos, políticos e sociais?

Consideramos que questões como estas se mostraram pertinentes ao demandarem a interpretação dos impactos sociais de processos industriais que envolvem a transformação de energia.

2) Inclusão de conteúdos (5 inserções): documentos produzidos e divulgados pelo governo federal a fim de esclarecer os agentes sociais sobre as decisões a serem tomadas e fundamentar a tomada de decisão possuem informações valiosas sobre como os fenômenos naturais e suas implicações econômicas têm sido geridos pelas instituições políticas. Considerando que o Ensino de Ciências pode se beneficiar de tais informações para operar conexões férteis entre ciência, tecnologia, sociedade e gestão ambiental, adaptamos quadros e tabelas e formulamos textos concisos capazes de oferecer dados relevantes e contextualizados na nova versão do material didático produzido. Foram inseridos, por exemplo, um gráfico disponível no Balanço Energético Nacional (BRASIL, 2011a, p. 163) sobre a distribuição da matriz energética mundial nos 
anos de 1973 e 2008, e um gráfico disponível no PDE 2020 (BRASIL, 2011c, p. 53) sobre a projeção de demanda de etanol para o Brasil entre os anos de 2011 e 2020. Outra inserção foi uma tabela do PDE 2020 (BRASIL, 2011c, p. 31) sobre a evolução da capacidade instalada por fonte de geração no Brasil, acompanhada deste texto explicativo:

\begin{abstract}
A tabela acima apresenta a previsão da capacidade de geração de energia para diversas fontes diferentes. Podemos perceber pela tabela apresentada que, no geral, a maioria das fontes sofre acréscimos ou decréscimos regulares, ou então se mantém praticamente constante. Podemos atribuir esses acréscimos constantes a planos de investimentos públicos ou privados e aumento de produção, e os decréscimos a diminuição de utilização de determinada fonte. Com relação a isso, gostaríamos de chamar atenção para as previsões de capacidade da fonte hidráulica para 2015 e do urânio em 2016. Ressaltamos esses dois casos porque eles representam respectivamente as previsões para inaugurações da Usina Hidrelétrica de Belo Monte no rio Xingu no estado do Pará, e da Usina Nuclear Angra 3, no estado do Rio de Janeiro.
\end{abstract}

A inserção deste texto no material experimental se assenta sobre a expectativa de que a Usina de Belo Monte, foco frequente dos meios de comunicação, poderia representar um incentivo para o debate de questões estimulantes em sala de aula, capazes de relacionar o fenômeno natural da transformação de energia com seus antecedentes e impactos sociais.

3) Formulação de novas questões para novos conteúdos (4 inserções): a inserção de informações de documentos de política pública como o Balanço Energético Nacional (BRASIL, 2011a) e do próprio PDE 2020 (BRASIL, 2011c) foi considerada adequada no material experimental para proporcionar vínculos objetivos entre os fenômenos naturais e a gestão de seus impactos sobre a sociedade diante de exigências de eficiência e economia. As informações inseridas foram acompanhadas de questões específicas, dirigidas a incentivar a reflexão sobre ligações possíveis entre o empreendimento científico e as políticas públicas de gestão de C\&T. Foi inserida, por exemplo, uma tabela presente no Balanço Energético Nacional (BRASIL, 2011a, p. 16) sobre a oferta interna de energia elétrica por fonte para o Brasil no ano de 2010, acompanhada desta questão: "se você pudesse contribuir para a tomada de decisões no que diz respeito às fontes de energia utilizadas pelo Brasil, qual você escolheria como a fonte para ser utilizada em maior escala e por quê?".

4) Reorganização de atividades em função da inclusão de questões (2 inserções): as Situações de Aprendizagem possuem uma lógica particular para orientar a prática de ensino, e a disposição de seus vários elementos em um roteiro prévio foi eventualmente 
afetada pela proposição de novos conteúdos e questões. Foi necessário, assim, realocar recursos e questões para preservar a dinâmica de seu desenvolvimento.

5) Orientações ao professor para conduzir a aula (10 inserções): nesta dimensão, apenas o Caderno do Professor sofreu intervenções, destinadas a fundamentar a prática docente com indicações substantivas, com acréscimos de: argumentos que relacionam os fenômenos naturais, seus impactos sociais e econômicos e a necessidade de uma resposta da sociedade através da gestão pública; informações do PDE 2020 que demonstram como determinada linha de ação política implica decisões de grande repercussão, a serem tomadas democraticamente; e sugestões para o docente se referir às consequências das políticas de energia sobre o cotidiano dos alunos, de forma a construir ligações explícitas entre a escola e a vida. Na Situação de Aprendizagem 7 do Caderno do Aluno (2009a), por exemplo, em uma questão sobre o porquê de economizar energia no país, foram inseridas, no material experimental, orientações para o professor abranger processos ambientais, aspectos econômicos, políticos e sociais envolvidos.

A fim de investigar a adequação do material didático reelaborado pelas intervenções efetuadas nestas cinco dimensões, aplicamos a técnica de grupo focal, que nos permitiu a discussão ativa com sujeitos dotados de vivências e experiências com o Ensino de Física no nível médio para fazer emergir "uma multiplicidade de pontos de vista" (GATTI, 2005, p. 9). A presença simultânea dos participantes, sem um roteiro fechado, possibilita a troca de ideias e enriquece a qualidade dos dados.

Segundo Gatti (2005), no âmbito das abordagens qualitativas em pesquisa social o grupo focal vem sendo cada vez mais utilizado. A técnica se baseia em um trabalho com um grupo de participantes pré-selecionados que possuam determinadas características em comum, desejadas pelo pesquisador, além de também possuir vivência com o tema a ser discutido. Mas ainda deve existir suficiente variação para que apareçam opiniões diferentes ou divergentes, com o objetivo de enriquecer as discussões. O grupo focal, por abrir oportunidade aos participantes para a exposição espontânea e com menos restrições de espaço e tempo de suas perspectivas, pode incentivar a elaboração de respostas mais completas em relação àquelas que seriam obtidas por meio de questionários, permitindo ao pesquisador a obtenção de um conhecimento mais profundo dos pontos de vista dos públicos sondados (TRIVIÑOS, 1987). 
Os depoimentos dos participantes do grupo focal foram registrados e estudados a partir da análise de conteúdo, que nos permitiu buscar o real significado pretendido pelos emissores e realizar inferências sobre sentidos implícitos (FRANCO, 2007; BARDIN, 2011).

O emprego da análise de conteúdo se mostra interessante uma vez que permite o estudo de motivações, orientações, valores e crenças (BARDIN, 2011), que podem não ser diretamente identificáveis na comunicação dos indivíduos.

O ponto de partida da análise de conteúdo é a mensagem, seja ela verbal (oral ou escrita), gestual, silenciosa, documental etc. Essa mensagem expressa um significado que pode ser investigado por meio da utilização da análise de conteúdo.

Bardin (2011) assinala três etapas básicas para o trabalho com a análise de conteúdo: a pré-análise, a descrição analítica e a interpretação inferencial.

A pré-análise é, basicamente, a organização do material. Corresponde a um conjunto de buscas iniciais que tem por objetivo sistematizar os conteúdos a serem trabalhados. Essa primeira fase possui, geralmente, três incumbências: escolha dos documentos a serem analisados, formulação de hipóteses ou objetivos e elaboração de indicadores que fundamentem a interpretação final (FRANCO, 2007, p. 51).

A descrição analítica se caracteriza por submeter o corpus de pesquisa a um estudo aprofundado, orientado em princípio pelas hipóteses presentes no referencial teórico envolvido (TRIVIÑOS, 1987, p. 161). Nessa fase, ocorrem a codificação, classificação e categorização das informações contidas no corpus da pesquisa (BARDIN, 2011).

A interpretação inferencial é a fase de análise do material produzido. É aqui que se estabelecem as relações entre o material produzido e os sentidos que dele são extraídos, à luz do referencial teórico utilizado.

\section{Encontros dos grupos focais}

Sete encontros realizados com a metodologia de grupo focal se realizaram no período compreendido entre outubro e dezembro de 2012. Os primeiros dois encontros ocorreram nas instalações da Diretoria Regional de Ensino da cidade de Bauru (SP), com professores de Física da região, presentes para a realização de uma orientação técnica promovida pela própria diretoria, na qual se incluiu a realização do grupo focal com autorização oficial. Os demais encontros ocorreram em duas escolas públicas da rede estadual de ensino localizadas em áreas urbanas de baixa renda da mesma cidade. 
No total, participaram 17 professores da rede pública de ensino (Tabela 1), compondo um grupo com formação em áreas diversas, que favoreceu discussões em torno da relevância do enfoque interdisciplinar sobre o tema da produção de energia.

Tabela 1 - Características dos professores participantes dos grupos focais

\begin{tabular}{cccc} 
Sexo & formação & experiência (anos) & disciplinas ministradas \\
M & Física e Filosofia & 25 & Física, Química e Ciências \\
M & Química & 5 & Física, Química e Matemática \\
\hline F & Química e Matemática & 8 & Física e Química \\
F & Biologia & 7 & Física, Biologia e Ciências \\
M & Sociologia & 10 & Filosofia, Matemática e Ciências \\
M & Física & 6 & Física \\
\hline M & Física & 12 & Física \\
\hline F & Letras & 12 & Gramática e Inglês \\
M & Física & 18 & Física e Química \\
F & Física & 22 & Física \\
\hline F & Biologia & 9 & Física e Ciências \\
M & Matemática & 15 & Física e Matemática \\
\hline M & Educação Física & 7 & Educação Física \\
\hline F & Física e Administração de empresas & 21 & Física e Matemática \\
\hline M & Matemática & 13 & Física e Matemática \\
\hline F & Matemática e Filosofia & 10 & Física, Matemática e Ciências \\
M & Biologia & 19 & Física, Química e Biologia \\
Fonte: elaboração própria & &
\end{tabular}

Os professores participantes dos grupos focais serão nomeados entre P1 e P17, em ordem diferente daquela apresentada na Tabela 1, para evitar a possibilidade de sua identificação.

\section{Resultados e discussão}

Os resultados dos grupos focais são apresentados e discutidos de acordo com quatro eixos organizadores, a saber:

1) Avaliação de características presentes no material didático original e seu potencial para desenvolvimento de relações entre ciência, tecnologia e sociedade;

2) A realidade escolar extraclasse, sua influência sobre a prática docente e os limites para o desenvolvimento de relações entre ciência, tecnologia e sociedade no material didático;

3) A formação do professor e os limites da função docente como obstáculos ao desenvolvimento de relações entre ciência, tecnologia e sociedade; 
4) A perspectiva da formação crítica e a contribuição do material didático reformulado experimentalmente.

Os três primeiros eixos reúnem considerações sobre as condições factuais encontradas pelas Situações de Aprendizagem reformuladas. O último eixo sintetiza a apreciação do material didático proposto.

1) Avaliação de características presentes no material didático original e seu potencial para desenvolvimento de relações entre ciência, tecnologia e sociedade.

Os participantes dos grupos focais demonstraram possuir visões globais a respeito do que julgavam como certo e errado no material didático em questão pressupostos que já poderiam dificultar a adoção de perspectivas CTS de formação para a cidadania, em particular a necessária interdisciplinaridade. Uma crítica recorrente dirigiu-se à alegada fragmentação do conteúdo por disciplinas e séries diferentes, o que prejudicaria a adoção de estratégias interdisciplinares de ensino:

P2: Se você for trabalhar interdisciplinarmente, o material tem que estar preparado. Não adianta estar escrito lá que se deve pregar por um ensino interdisciplinar, mas daí o caderninho de Física não tem nada a ver com o que está sendo visto no de Química, nem no de Biologia. Os assuntos às vezes não estão nem no mesmo ano, por exemplo, você vê átomo em Química no primeiro ano, já em Física você só vai ver alguma coisa desse tipo no terceiro ano. Isso se der tempo ainda, porque essa parte de Física moderna geralmente nem é dada.

P8: Nos grupos que trabalharam os caderninhos (...) não teve interação. A desconexão está na própria formação do material. A gente percebe que não existiu contato entre os grupos que montaram os conteúdos.

P15: O Estado pede interdisciplinaridade, mas o material não colabora para isso.

Em especial, é possível sustentar que P8 e P15 reconhecem a importância da interdisciplinaridade e o compromisso do material didático oficial com sua promoção, mas julgam que a elaboração do material aplicou de forma insuficiente tal princípio.

Outra crítica frequente se dirigiu às alegadas discrepâncias entre a distribuição dos conteúdos e o tempo estipulado para seu cumprimento. Para alguns professores, o tempo disponível não seria suficiente para cumprir o programa previsto no material didático, o que os levava eventualmente a abandoná-lo, apesar de reconhecer sua utilidade.

P11: Precisava de mais Física, mais Química, mais Biologia, mais Ciências. Mas, com o tanto de aula que a gente tem, o caderninho já é muita coisa. Não tem como cumprir tudo.

P2: Eu vejo assim, nós não podemos jogar fora. Nós temos que enriquecer o caderninho, porque é ele que vai com a gente para aula.

P16: A ideia do caderninho em si não é ruim. Para falar a verdade, ela é extremamente interessante. O problema é que, na hora que foi ao papel, algumas coisas não deram certo. 
Estes posicionamentos, que sugerem o descolamento entre as expectativas dos elaboradores do material didático oficial e a viabilidade de sua aplicação na realidade cotidiana do Ensino de Ciências, apesar de revelarem críticas ao material didático em si mesmo, parecem se dirigir principalmente ao contexto formado pelo material e a realidade escolar em que ele e o próprio professor estão inseridos, ou seja, mais às dificuldades de uso do material e menos em relação à sua concepção, aspecto aprofundado no próximo eixo.

2) A realidade escolar extraclasse, sua influência sobre a prática docente e os limites para o desenvolvimento de relações entre ciência, tecnologia e sociedade no $\underline{\text { material didático. }}$

As críticas dos participantes dos grupos focais não foram direcionadas especificamente ao material didático reformulado experimentalmente conforme apontado acima, mas sim à realidade subjacente de obstáculos à sua potencial utilização. No entanto, muitas vezes os professores aparentemente não perceberam que o foco de sua crítica estava além do próprio material, deixando de reconhecer as influências sobre sua prática docente. O currículo em si, para além dos Cadernos, já se apresentava como um problema, pelo fato de os professores não o considerarem condizente com o número de aulas disponíveis para as disciplinas das Ciências Naturais e Matemática. Alguns participantes, embora tenham reconhecido a importância das intervenções no material didático destinadas a estabelecer relações com o PDE 2020, alegaram falta de tempo para sua devida utilização.

P9: Nenhuma sequência didática organizada pelo material (em sua versão oficial) atende à demanda de sala de aula.

P8: O currículo para o Ensino Médio foi finalizado depois da produção dos caderninhos, então o currículo tem conteúdos que não estão nos caderninhos. P9: O número de aulas previstas pelo caderninho também não é suficiente. $\mathrm{O}$ currículo está mais coerente com o livro didático. Se você ficar só no caderninho, vai ficar com uma defasagem bem maior do que se você usar o livro didático. Aí você tem uma demanda muito grande para adequar a proposta de atividade do caderno com aquilo que você tem que colocar para sua sala de aula, acaba sendo um trabalho de pesquisa, de elaboração, que os professores estão fazendo.

P2: Quando a gente tem tempo para ir atrás de dados para apresentar para os alunos? A escola, do jeito que está estruturada, não deixa. A gente dá aula aqui, dá aula ali, corrige prova, faz trabalho, corrige tarefa, prepara aula, (e) além de fazer tudo isso ainda vive em uma pindaíba danada.

P1: Quando chega na Química, a maioria das atividades do caderninho precisa de um laboratório. Eu não tive como usar o caderninho de Química esse ano. A escola não tem laboratório.

P5: A ideia de formar um cidadão crítico fica para escanteio. Ele precisa saber lá operações fundamentais da Matemática, precisa conseguir ler e interpretar um texto, e nem isso ele consegue. Você está formando o cara para se encaixar no mercado de trabalho, não tem a ver com formar o cidadão. Isso é coisa para médio e longo prazo, não é para agora. 
P17: O próprio sistema não deixa a coisa se aprofundar. Parece que as questões da escola são muito superficiais, por n motivos diferentes. Eu tenho duas aulas de Física por semana, duas de Química. O que eu vou fazer com isso? Como é que eu explico o átomo, por exemplo? É uma ideia extremamente abstrata e (o aluno) nunca foi treinado para pensar desse jeito. Eu não vejo uma formação científica de fato que incentive a pesquisa, elaborar um texto, o pensar sobre.

P12: Um dos problemas é que o aluno não foi instigado, incentivado. Ele está acostumado a entrar na escola para estudar, mas saiu dali acabou. Ele não entende que a leitura de um texto, assistir a um programa de TV, uma conversa é uma forma de aprendizado que pode ser utilizada na escola.

Em particular, P17 e P12 parecem denunciar o que perceberiam como incômoda contradição entre as expectativas depositadas pela sociedade sobre seu trabalho e as condições objetivas oferecidas pela escola para seu desempenho, incluindo, de forma indireta, o material didático oficial. As dificuldades envolveriam tanto a necessidade de sobrecarregar a jornada de trabalho em busca de proventos, como apontado por P2, quanto as carências estruturais das escolas, como indicado por P1.

Outro dado importante que emergiu das discussões realizadas nos grupos focais esteve relacionado à adequação da formação docente diante dos desafios do Ensino de Ciências segundo as perspectivas CTS, em particular em relação à adoção do material reformulado experimentalmente, e a preparação para o exercício crítico da cidadania, aspecto desenvolvido no próximo eixo.

3) A formação do professor e os limites da função docente como obstáculos ao $\underline{\text { desenvolvimento de relações entre ciência, tecnologia e sociedade. }}$

Com frequência, os participantes dos grupos focais questionaram a qualidade da formação universitária. O profissional egresso das instituições de nível superior está preparado para exercer a função docente? Por que a universidade não se aproxima das escolas? Quem são os formadores de professores nas universidades? Os contornos de tais questionamentos podem ser percebidos nas seguintes falas, que discorrem sobre a possibilidade de o professor orientar o aluno na construção de ligações entre as ciências e seu cotidiano, a partir do material reformulado experimentalmente:

P9: Quem dos nossos colegas professores faz a leitura de um artigo científico? Nem Superinteressante pega.

P2: E como trazer o diálogo para sala de aula, a possibilidade de debate, trabalhar com questões abertas, se esse professor não consegue nem dialogar com os colegas? Ele não sabe ouvir, está sempre certo, e ai de você se discordar dele.

P15: Na faculdade, eu tive um mundaréu de disciplinas técnicas extremamente complicadas... Onde eu uso tudo isso na escola? O currículo precisava ser revisto, mas também se complicar muito a coisa os alunos não têm base para acompanhar. Não estamos formando professores, estão sendo 
formados bacharéis que podem dar aula. Quando os professores chegam aqui para dar aula é que eles vão aprender a dar aula de fato.

P7: O fato é o seguinte: tem que aumentar a pesquisa pedagógica da área que ele está estudando. Talvez diminuir a parte técnica seja muito extremista, mas a questão pedagógica, filosófica, precisava ser melhor trabalhada.

P12: Qual é a proximidade das universidades com a escola? Por que esse distanciamento de onde a gente vai trabalhar?

P11: Você vê comentários de colegas de trabalho que ainda estão concluindo a faculdade, de que o professor de didática nunca pisou em uma sala de aula de uma escola pública. Que formação ele está passando?

P12: Exatamente, eles não fazem parte dessa realidade. Eles supõem, baseados nos teóricos, que também não estão aqui, que a coisa funciona de determinado jeito. Daí a culpa cai em quem? Cai no professor. Se tem pesquisa mostrando como é que tem que fazer, o errado é o professor que não consegue fazer o que está lá.

Estes trechos exemplificam como os professores consideram os limites de sua qualificação para uma atuação mais sintonizada às exigências de formação para cidadania. Podemos inferir, em particular de P9 e P15, a existência de uma crítica generalizada à formação docente, que não favoreceria necessariamente a reflexão sobre as condições sociais e políticas de produção e gestão de C\&T.

Ainda foram notadas indicações de que tais limites parecem não comprometer o reconhecimento da relevância da formação cidadã, embora muitos não se sintam preparados para colocá-la em prática.

P1: Eu acho que isso aí (a formação cidadã) já é questão da Sociologia. Nossa formação é muito limitada. No próprio quesito científico, ela deixa a desejar. Tem assunto no caderninho de Física que a gente tem dificuldade. Astronomia (e) Física moderna são assuntos que eu não vi na faculdade.

P4: Não sei como ensinar o aluno a ser crítico.

P12: O aluno precisa disso. Não adianta a gente ficar lá passando fórmula para ele decorar, exerciciozinho mecânico para ele resolver. Não adianta, não tem significado. Na faculdade, se bobear você sai mais alienado do que quando entrou (...). Por isso que eu tento conversar com os meus alunos, explicar, trazer problemas de fora, mas é difícil. Você começa a discutir, daí aparece alguma coisa diferente de biologia, ele vai e pergunta para o professor de biologia, daí já viu... Já aconteceu de um colega ficar bravo comigo porque os alunos ficavam levando dúvidas que surgiam na minha aula, e não eram da minha área, para ele responder.

Estes recortes delimitam um panorama das discussões que surgiram durante a realização dos grupos focais, sobre aspectos como as impressões dos professores em relação ao material didático já existente e a influência da formação profissional sobre seu desempenho no uso dos Cadernos. No último eixo, estão reunidos trechos específicos dos depoimentos sobre as propostas de modificação ao material didático. 
4) A perspectiva da formação crítica e a contribuição do material didático $\underline{\text { reformulado experimentalmente. }}$

Antes da realização dos grupos focais, com pelo menos uma semana de antecedência, os professores participantes receberam o material didático com as modificações propostas, a fim de que tivessem tempo para conhecê-lo e começassem a formar suas opiniões a respeito dele.

No primeiro encontro, apresentamos e discutimos com os professores a primeira atividade da Situação de Aprendizagem 7 do Caderno do Aluno (SÃO PAULO, 2009a), que consiste em um texto no qual são abordados os processos de degradação da energia envolvidos no funcionamento de um motor a combustão. Procuramos deixar sempre muito claro o que já era existente no material didático (texto e primeira questão), e o que se caracterizava como as propostas de aperfeiçoamento que criamos para o material. Também ressaltamos a utilização dos documentos oficiais que contêm os elementos ali presentes, tanto o Balanço Energético Nacional (BRASIL, 2011a) quanto o Plano Decenal de Expansão de Energia 2020 (BRASIL, 2011c), e os explicamos brevemente.

A discussão centrou-se em especial nas questões presentes na proposta de reformulação do material didático. Debatemos as dificuldades relacionadas ao trabalho com questões abertas, como a exigência de interdisciplinaridade, e de contextualizar a aula diante da realidade extraescolar. Em particular, alguns professores expressaram seu receio em lidar com questões abertas, que envolvem conhecimentos de diversas áreas:

\footnotetext{
P10: O aluno não consegue trazer o que é de fora para dentro da escola e nem levar a escola para fora.

P1: O que acontece aí é que o professor tem que saber Física, Química, Biologia, História...

P4: Exatamente, fazer a interação.

P1: Ele pode chegar lá para falar de fotossíntese e falar de energia também.

P2: É complicado. E se ele não souber a resposta?

P1: Ele perde a autoridade na questão de ser dono do conhecimento.

P4: Mas os alunos não querem que isso aconteça. Esse conceito está sendo bastante difundido, de o professor não ser o detentor do conhecimento, mas no momento que você chega em uma sala de aula e fala "eu não sei isso", os alunos já passam a te olhar de outra forma, eles não têm mais confiança em você, mesmo eles entendendo que isso seria o mais adequado. E, hoje em dia, se você perde a confiança da sala, acabou, você não consegue fazer mais nada.
}

Falas como as de P1 e P4 sugerem que um dos mitos relacionados às interações entre CTS e educação científica segundo a revisão de Auler e Delizoicov (2001), qual seja, o do mérito do modelo de decisão apoiado sobre a suposta superioridade da ciência, é convenientemente reafirmado por docentes que dependem da manutenção dessa crença entre seus alunos para preservar sua autoridade em sala de aula. 
As críticas às propostas de modificação que apresentamos aos professores se mostraram mais pontuais. Notamos um consenso de que as propostas estavam de acordo com a perspectiva de ensino para a formação crítica dos alunos. Mas houve questionamentos sobre a viabilidade da abordagem.

P10: Suas atividades estão excelentes para aquilo a que você está se propondo. Só que para responder essas questões, os alunos já têm que ter uma bagagem, tem que saber um pouco a respeito do etanol do Brasil, dos Estados Unidos. E, como a gente sabe que os alunos não têm leitura, vai ficar um pouco mais difícil.

P8: Tem muita coisa na escola que dificulta isso, mas você não pode desanimar.

P1: Eu acho que aqui não seria uma questão para ser trabalhada unicamente pela Física. Aqui eu acho que a Geografia tinha que ser inclusa para poder justificar essa parte dos processos humanos de produção e transformação de energia, porque vai afetar a economia.

P2: Toma cuidado com a linguagem. Pode parecer que não, mas irreversível ia ser difícil para eles, porque apesar de a gente falar, explicar, eles não fixam esse tipo de informação.

P1: Eu sinceramente acho que não pode abrir mão dessas coisas. É a linguagem envolvida com o que está sendo abordado.

P3: É, se a gente voltar ao nível do aluno, eles nunca vão crescer intelectualmente. E a gente tem que tentar fazer com que eles cresçam nesse sentido: melhorar o vocabulário, a leitura. Não sabe o que significa, vai no dicionário, vai no Google, tem que aprender a pesquisar.

P9: Quando a gente amplia muito o número de atividades, o aluno não alcança e você também não dá conta enquanto professor. Sua ideia está boa, mas do jeito que está a escola, você vai ter um pouco de dificuldade.

Estes depoimentos sugerem que, contraditoriamente, as limitações ao aperfeiçoamento do material didático provêm dos limites da própria escola no cenário atual. Quando o professor alega ter dificuldade em utilizar os Cadernos porque seus alunos não possuem o domínio necessário de leitura e compreensão de texto e não estão habituados a refletir e pesquisar, não são problemas que possam ser atribuídos diretamente aos Cadernos. São problemas situados no contexto de atuação da escola diante das competências do aprendiz, caracterizadas por hábitos irregulares de leitura e busca por informações.

Neste sentido, cabe estabelecer uma demarcação entre quais são os problemas levantados pelos professores que podem ser atribuídos ao material didático, ou mesmo quais são os problemas que podem ser combatidos diretamente por seu aperfeiçoamento, e quais problemas que, embora influenciem sua utilização, estão além de sua capacidade e alcance. Deficiências de infraestrutura, como falta de laboratórios, de material, de computadores, a dificuldade de o aluno estabelecer relações entre a escola e o mundo para além da escola, a dificuldade de leitura e interpretação de texto, a falta de familiaridade com as operações matemáticas básicas e as limitações da 
formação docente são problemas que, por mais sérios que sejam e por mais que influenciem a utilização do material didático, não podem ser atribuídos ao próprio material.

Para alguns desses problemas, o material didático pode exercer papel importante na resolução, como no caso de habilidades insuficientes de leitura, interpretação de texto e operações matemáticas básicas, mas mesmo para esses deve existir uma mudança em maior escala.

Para o caso da falta de infraestrutura das escolas, por mais que não seja objetivo desse trabalho discutir esse tipo de situação, devemos ter claro que, nos locais em que se apresenta, esse problema se mostra como empecilho para o exercício digno e satisfatório da prática docente. Tais limitações podem ser contornadas com imaginação e boa vontade? Em alguns casos sim, mas a profissão docente não deveria ser rebaixada a um nível em que a imaginação e a boa vontade do professor devam ser maiores que sua qualificação profissional.

Quanto aos problemas apontados pelos professores que podem ser considerados diretamente relacionados ao material didático, podemos citar, como o mais recorrente durante a realização dos grupos focais, a fragmentação dos conteúdos por disciplinas e séries distintas, que dificultaria o trabalho dentro da própria disciplina, afetaria o diálogo de determinada disciplina com as demais e poderia prejudicar abordagens interdisciplinares.

Podemos sustentar que estes problemas resultariam inadvertidamente no reforço dos mitos apontados pela revisão de Auler e Delizoicov (2001) no contexto da educação científica. Isto é, quando o conhecimento científico é oferecido na forma de pacotes disciplinares de ensino isolados, com escasso diálogo com a realidade política, social e econômica com a qual se relaciona, ajusta-se a um contexto pedagógico no qual não se põe em questão a crença na superioridade do modelo de decisões tecnocráticas. Mantêm-se a perspectiva salvacionista atribuída à ciência e tecnologia e o sentido de determinismo tecnológico que parece orientar a compreensão de seus efeitos. Este cenário conduziria à celebração da tecnologia como causa unívoca das mudanças sociais, sem conexões aparentes com os outros fatores que a influenciam - conexões que poderiam ser indicadas em situações de ensino elaboradas de forma a conter, entre seus objetivos, a promoção do diálogo interdisciplinar e o exame de relações com os diversos contextos que orientam a produção de C\&T. 
Vale ressaltar que, apesar das críticas pontuais, os professores participantes dos grupos focais reconheceram a pertinência do material didático proposto e seu caráter promissor de contribuição para a formação de um cidadão crítico. Assim, embora no desenvolvimento dos grupos focais não tenham sido traçadas conexões explícitas entre os aspectos teóricos da educação CTS e o potencial do material didático proposto na promoção da interdisciplinaridade e do diálogo com a realidade social, econômica e política, podemos inferir do conjunto das perspectivas dos participantes que existe um potencial de receptividade positiva a transformações que venham a sustentar alternativas práticas à fragmentação do conhecimento no Ensino de Ciências.

Em resposta às questões de pesquisa enunciadas inicialmente, cabem reflexões. De que maneira o ensino formal poderia contribuir para a preparação de indivíduos aptos a compreender as questões em jogo e expressar suas perspectivas em consultas públicas? A partir do momento em que o aluno é familiarizado no ambiente escolar com o contexto da participação política promovida por consultas públicas, existe a possibilidade de ampliar a reflexão para o ambiente extraescolar. Como o Ensino de Ciências Naturais poderia comportar o desenvolvimento de Situações de Aprendizagem que envolvam o tratamento de questões relativas à compreensão das escolhas subjacentes às políticas nacionais de $\mathrm{C} \& \mathrm{~T}$ ? Entre outras formas possíveis, a sugestão aqui delineada envolve o aperfeiçoamento de materiais pedagógicos oficiais, incluindo a reformulação de situações de aprendizagem que envolvam o conteúdo abordado, para que façam referência direta às novas formas de participação política já em prática no Brasil, em particular as consultas públicas. De que maneira aspectos da formação para a cidadania, considerada como exercício de direitos civis, políticos e sociais nas sociedades democráticas contemporâneas, poderiam ser contemplados pelo Ensino de Ciências Naturais? Por meio da relação entre tópicos de ensino, como produção e consumo de energia elétrica, e as estruturas econômicas que, regidas por arranjos políticos e interesses dos diversos setores da sociedade, determinam os usos sociais de C\&T. Naturalmente, não é o caso de apostar unicamente no potencial dos materiais didáticos, ignorando necessidades prementes de áreas como formação de professores e gestão escolar. Mas, à medida que os próprios materiais também não podem ser ignorados, revelam-se um meio potencial de transformação. 


\section{Considerações finais}

Este artigo descreveu os resultados de pesquisa que envolveu uma reflexão em torno da indicação de aperfeiçoamentos para os Cadernos do Aluno e do Professor, material didático oficial do Ensino de Física utilizado nas escolas paulistas, e sua posterior avaliação por professores em grupos focais.

As mudanças foram propostas para duas Situações de Aprendizagem dos Cadernos sobre o tema da entropia e degradação de energia, parte integrante da Proposta Curricular do Ensino Médio do Estado de São Paulo, e trouxeram referências ao Plano Decenal de Expansão de Energia (PDE) 2020, documento de política pública posto em consulta online pelo Ministério de Minas e Energia em 2011

A utilização do PDE 2020 (BRASIL, 2011c) como pretexto para a proposta de aperfeiçoamento do material didático foi valorizada pelos professores. A ideia de contextualizar um documento oficial de política pública em sala de aula, evidenciando sua submissão a uma consulta pública online e a oportunidade de participação política dali decorrente, se revelou um fator de profunda motivação aos professores, devido à intensificação que traz à relevância da formação escolar crítica.

Os resultados sugerem que o material reformulado foi bem aceito pelos professores participantes dos grupos focais, mas houve ressalvas à viabilidade de sua aplicação no quadro das atuais limitações da escola e da formação docente.

Os professores admitiram a importância do Ensino de Ciências na formação de cidadãos críticos. Mas alertaram para as dificuldades impostas por alunos dotados de escassas habilidades de leitura e compreensão de texto e uma formação docente insuficiente em relação às estratégias didáticas capazes de colocar em prática o Ensino de Ciências sob as perspectivas CTS.

Algumas das críticas registradas nos grupos focais vão ao encontro do que foi colocado por Pedretti (2003) como dificuldades encontradas por professores canadenses em atividades de ensino CTS, referentes ao trabalho com questões abertas; à exigência de relacionar a realidade extraescolar com os conteúdos curriculares; à realização de debates éticos e de valores; à construção de relações entre local e global; à dificuldade do professor em abrir mão da sua posição de controle em aula para conceder autonomia ao aluno.

Consideramos que o material produzido atende o que foi apresentado por Santos e Mortimer como sendo objetivo de uma educação CTS, segundo a qual cabe auxiliar os alunos a "[...] construir conhecimentos, habilidades e valores necessários para tomar 
decisões responsáveis sobre questões de ciência e tecnologia na sociedade e atuar na solução de tais questões" (SANTOS; MORTIMER, 2002, p. 136). Explorar a realidade social em sala de aula pode colaborar com o objetivo de caracterizar a ciência e suas relações com a tecnologia e a sociedade como um processo não neutro e influenciável pela ação do homem, tal como foi salientado por López Cerezo (2004), o que contribuiria para a tomada de decisões de maneira informada e responsável, possibilitando ainda a ação sobre as decisões.

De modo a refletir brevemente sobre as implicações e recomendações da pesquisa descrita neste artigo para a prática da educação CTS, podemos sugerir que, embora os fatores que conduzem à fragmentação do Ensino de Ciências sejam complexos e multifacetados, encontrando-se imbricados em desafios difíceis de serem discernidos, pode ser produtivo desenvolver abordagens dedicadas a incentivar transformações pontuais, gradualmente. Isto porque muitas falas dos participantes dos grupos focais denotam um quadro aparentemente insolúvel. Alguns professores veem fatores distintos como elementos de um mesmo conjunto de barreiras que os separam da atuação desejada.

A dificuldade de visualizar causas separadamente parece desencorajar o engajamento em saídas possíveis e gerar imobilismo e conformismo. Por isso, identificar fatores específicos e sua influência sobre a performance docente pode ser importante para ajudar a repensar a própria atuação. A contribuição deste artigo foi indicar de que forma o material didático pode vir a ser um aliado na busca de objetivos do Ensino de Ciências sob a perspectiva do enfoque CTS, sem desconhecer que seu potencial não pode ser apreciado de forma desconectada das condições objetivas de sua aplicação na escola brasileira atual.

Para além das limitações apontadas, os professores participantes dos grupos focais reconheceram a possibilidade de que melhorias no material didático oficial tragam uma contribuição efetiva ao Ensino de Ciências em direção à formação para cidadania. Sobretudo, reconheceram que, apesar das deficiências de formação docente e competências discentes, a busca pela educação cidadã também é uma tarefa que lhes cabe enquanto formadores, e que é possível encontrar motivação para suprir as deficiências. 


\section{Agradecimentos}

Os autores agradecem à Capes - Coordenação de Aperfeiçoamento de Pessoal de Nível Superior pela bolsa de mestrado concedida e aos pareceristas anônimos deste periódico pelas indicações precisas.

\section{Referências}

ACEVEDO, J. A. D. Reflexiones sobre las finalidades de la enseñanza de las ciencias: educación científica para la ciudadanía. Revista Eureka sobre Enseñanza y Divulgación de las Ciencias, v. 1, n. 1, p. 3-16, 2004.

ACEVEDO, J. A.; VÁZQUEZ, A.; MARTÍN, M.; OLIVA, J. M.; ACEVEDO, P.; PAIXÃO, M. F.; MANASSERO, M. A. Naturaleza de la ciencia y educación científica para la participación ciudadana. Una revisión crítica. Revista Eureka sobre Enseñanza y Divulgación de las Ciencias, v. 2, n. 2, p. 121-140, 2005.

AIKENHEAD, G. S. STS Education: a rose by any other name. In: CROSS, R. (Ed.). A Vision for Science Education: Responding to the Work of Peter J. Fensham. Routledge Press, 2003. p. 59-75.

AULER, D. Alfabetização científico-tecnológica: um novo "paradigma"? Ensaio. Pesquisa em Educação em Ciências, v. 5, n. 1, p. 69-83, 2003.

AULER, D.; DELIZOICOV, D. Alfabetização científico-tecnológica para quê? Ensaio. Pesquisa em Educação em Ciências, v. 3, n. 2, p. 17-29, 2001.

BARDIN, L. Análise de conteúdo. São Paulo: Ed. 70, 2011.

BERNARDO, J. R. R.; VIANNA, D. M.; SILVA, V. H. D. A construção de propostas de ensino em Ciência - Tecnologia - Sociedade (CTS) para abordagem de temas sociocientíficos. In: SANTOS, W. L. P., AULER, D. (orgs.) CTS e educação científica: desafios, tendências e resultados de pesquisa. Brasília: Ed. UnB, 2011. p. 373 - 394.

BRASIL. MINISTÉRIO DA EDUCAÇÃO. Lei de Diretrizes e Bases da Educação Nacional, Brasília, DF, 1996.

BRASIL. MINISTÉRIO DA EDUCAÇÃO. Orientações curriculares para o ensino médio, v. 02, Brasília, DF, 2006.

BRASIL. MINISTÉRIO DE MINAS E ENERGIA. Balanço Energético Nacional 2011: Ano Base 2010, Brasília, DF, 2011a. Disponível em: https://ben.epe.gov.br/downloads/Relatorio_Final_BEN_2011.pdf. Acesso em: 13 de abril de 2015.

BRASIL. MINISTÉRIO DE MINAS E ENERGIA. Plano Decenal de Expansão de Energia 2020 - Sumário, Brasília, DF, 2011b. Disponível em: http:// http://www.epe.gov.br/pdee/forms/epeestudo.aspx. Acesso em: 13 de abril. 2015. 
BRASIL. MINISTÉRIO DE MINAS E ENERGIA. Plano Decenal de Expansão de Energia 2020, Brasília, DF, 2011c. Disponível em: http://www.epe.gov.br/pdee/forms/epeestudo.aspx. Acesso em: 13 de abril. 2015

CHASSOT, A. Alfabetização científica: uma possibilidade para a inclusão social. Revista Brasileira de Educação, ANPED, n. 26, p. 89-100, 2003.

FELT, U.; WYNNE, B. Taking European knowledge society seriously. Brussels: European Union, Directorate-General for Research, Science, Economy and Society, 2007.

FRANCO, M. L. P. B. Análise de conteúdo. 2 ed. Brasília: Líber Livro, 2007.

GATTI, B. A. Grupo focal na pesquisa em ciências sociais e humanas. Brasília: Líber Livro Editora, 2005.

GONZÁLEZ GARCÍA, M. I.; LÓPEZ CEREZO, J. A.; LUJÁN LÓPEZ, J. L. Ciencia, tecnología y sociedad: una introducción al estudio social de la ciencia y la tecnología. Madrid: Technos, 1996.

HAYASHI, M. C. P. I.; HAYASHI, C. R. M. FURNIVAL, A.C.M. Ciência, Tecnologia e Sociedade: Apontamentos preliminares sobre a constituição do campo no Brasil. In: SOUZA, C. M.; HAYASHI, M. C. P I. (orgs.). Ciência, Tecnologia e Sociedade: Enfoques teóricos e aplicados. São Carlos: Pedro e João Editores, 2008. p. 29 - 68.

HODSON, D. Time for action: Science education for an alternative future. International Journal of Science Education, v. 25, n. 6, p. 645-670, 2003.

IRWIN, A. STS perspectives on scientific governance. In: HACKET. E. J.; AMSTERDAMSKA, O.; LYNCH, M.; WAJCMAN, J. (eds.). The handbook of science and technology studies. Cambridge, MA: MIT Press, 2008. p. 583-607.

LEITE, A. C. O.; FERRAZ, M. C. C. Educação CTS: Reflexões sobre os conteúdos curriculares e as metodologias de ensino e aprendizagem. In MACHADO, W. A. Ciência, tecnologia e sociedade: desafios da construção do conhecimento. São Carlos: EdUFSCar, 2011. p. 39-50.

LEVINSON, R. A theory of curricular approaches to the teaching of socio-scientific issues. Alexandria - Revista de Educação em Ciência e Tecnologia, v. 1, n. 1, p. 133151 , março de 2008.

LÓPEZ CEREZO, J. A. Ciência, Tecnologia e Sociedade: o estado da arte na Europa e nos Estados Unidos. In: SANTOS, L. W. et al (org.) Ciência, tecnologia e sociedade: o desafio da interação. Londrina: IAPAR, 2004. p. 11-46.

PEDRETTI, E. Teaching Science, Technology, Society and Environment (STSE) education. Preservice teacher's philosophical end pedagogical landscape. In: ZEIDLER, D. L. (ed.). The Role of Moral Reasoning on Socioscientific Issues and Discourse in Science Education. Kluwer Academic Publishers, Netherlands, 2003. p. 219-239. 
PEDRETTI, E.; BENCZE, L.; HEWITT, J.; ROMKEY, L.; JIVRAJ, A. Promoting issues-based STSE perspectives in science teacher education: Problems of identity and ideology. Science \& Education, v. 17, n. 8/9, 941-960, 2008.

PIERSON, A. H. C. et al. Abordagem CTS na perspectiva de licenciados em química. Ciência \& Ensino, v. 1, n. especial, p. 1-10, 2007.

PRAIA, J.; GIL-PÉREZ, D.; VILCHES, A. O papel da natureza da ciência na educação para a cidadania. Ciência \& Educação, v.13, n. 2, p. 141-156, 2007.

ROTHBERG, D. Contribuições a uma teoria da democracia digital como suporte à formulação de políticas públicas. Revista Iberoamericana de Ciencia, Tecnología y Sociedad, v. 5, n. 14, p. 69-87, 2010.

ROTHBERG, D. Por uma agenda de pesquisa em democracia eletrônica. Opinião Pública, v. 14, n. 01, p.149-172, 2008.

SANTOS, L. W.; ICHIKAWA, E. Y. CTS e a participação pública na ciência. In: SANTOS, L. W. et al (org.) Ciência, tecnologia e sociedade: o desafio da interação, Londrina: IAPAR, 2004. p. 241-273.

SANTOS, L. W.; MORTIMER, E. F. Uma análise de pressupostos teóricos da abordagem C-T-S (Ciência - Tecnologia - Sociedade) no contexto da educação brasileira. Ensaio. Pesquisa em Educação em Ciências, v. 2, n. 2, p. 133-162, 2002.

SÃO PAULO (Estado). Secretaria da Educação - SEE. Caderno do Aluno; Física;

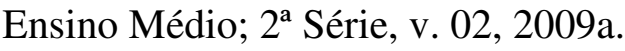

SÃO PAULO (Estado). Secretaria da Educação - SEE. Caderno do Professor, Física, Ensino Médio, 2a Série, v. 02, 2009b.

SÃO PAULO (Estado). Secretária da Educação - SEE. Currículo do Estado de São Paulo: Ciências da Natureza e suas tecnologias, 2010.

SOUZA, C. A.; BASTOS, F. P.; ANGOTTI, J. A. P. Cultura científico-tecnológica na educação básica. Ensaio, Pesquisa em Educação em Ciências, Belo Horizonte, v. 9, n. 1, p. 62-71, 2008.

SOUZA, R. F. Política curricular no estado de São Paulo nos anos 1980 e 1990. Cadernos de Pesquisa, v. 36, n. 127, p. 203-221, 2006.

TRIVIÑOS, A. N. S. Introdução à pesquisa em ciências sociais: a pesquisa qualitativa em educação. 1 ed. São Paulo, Editora Atlas, 1987.

WERTHEIN, J., CUNHA, C. (orgs.) Ensino de ciências e desenvolvimento: o que pensam os cientistas. 2.ed. Brasília: UNESCO, Instituto Sangari, 2009. 
DANILO ROTHBERG. Doutor em Sociologia pela UNESP - Universidade Estadual Paulista. Docente do Departamento de Ciências Humanas da Faculdade de Arquitetura, Artes e Comunicação da UNESP, Campus Bauru (São Paulo, Brasil), e do Programa de Pós-Graduação em Educação para Ciência da UNESP.

GABRIEL AUGUSTO CAÇÃO QUINATO. Graduado em Licenciatura Plena em Física pela UFSCar - Universidade Federal de São Carlos, Mestre em Educação para Ciência pela UNESP - Universidade Estadual Paulista, Campus Bauru, e doutorando no mesmo programa. Professor do Ensino Básico, Técnico e Tecnológico do IFPR Instituto Federal do Paraná.

Recebido: 01 de julho de 2015

Revisado: 08 de janeiro de 2016

Aceito: 03 de março de 2016 